\title{
Avaliação agronômica de variedades de feijão-caupi em cultivo de sequeiro no município de Coremas-PB
}

\section{Agronomic evaluation of cowpea varieties in rainfed crop in the municipality of Coremas-PB}

\author{
Daniel P. dos Santos ${ }^{1}$ e Lucas K. S. Lima ${ }^{2}$
}

\begin{abstract}
Resumo: O feijão-caupi caracteriza-se como uma das principais culturas de subsistência para os pequenos agricultores do Nordeste e Norte. No entanto o rendimento médio dessa cultura é considerado baixo, atribuído a utilização de baixa tecnologia e variedades não adaptadas as condições de produção. Assim este trabalho teve por objetivo avaliar a produtividade de variedades de feijão-caupi em cultivo de sequeiro no município de Coremas-PB. O experimento foi realizado na comunidade quilombola do sítio Barreiras município de Coremas estado da Paraíba, entre Fevereiro e Maio de 2014 . O trabalho foi constituído por quatro tratamentos (sempre-verde, roxinho, costela-de-vaca e garanjão). O delineamento experimental foi em blocos ao acaso, com cinco repetições. As variáveis analisadas aos 50 dias após semeadura foram produtividade de grãos, comprimento médio de vagem, número de grãos por vagem, peso médio de vagem, massa de 100 grãos. Os dados obtidos foram submetidos a análise e as médias comparadas pelo teste de Tukey a 5\% de probabilidade. Foi observada variação significativa para todas as variáveis analisadas. As variáveis aqui analisadas encontram-se acima das médias nacionais de produção, com destaque para o tratamento costela de vaca, que é uma variedade crioula mantida pelos pequenos agricultores da região, adaptada as condições locais apresentando rendimento superior quando comparado com as demais. Assim a variedade costela de vaca é recomendada para as condições de Coremas - PB.
\end{abstract}

Palavras-chave: crioulas, produtividade, semiárido, Vigna unguiculata, agricultura familiar

Abstract: Cowpea is characterized as one of the main subsistence crops for small farmers in the Northeast and North. However the average yield of this crop is considered low, given the use of low-tech and varieties not adapted to the conditions of production. Thus this work aimed to evaluate the productivity of cowpea varieties in rainfed crop in the municipality of Coremas-PB. The experiment was carried out in maroon community site Barriers Coremas municipality of the state of Paraíba, between February and May 2014 The work consisted of four treatments (evergreen, roxinho, rib-de-vaca and garanjão). The experimental design was a randomized block with five replications. The variables analyzed 50 days after sowing, seed yield, average length of pod, number of seeds per pod, pod weight, weight of 100 grains. Data were subjected to analysis and the means were compared by Tukey test at $5 \%$ probability. Significant variation was observed for all variables. The variables analyzed here are above national averages of production, especially for the treatment of cow rib, which is a creole variety maintained by small farmers in the region, tailored to local conditions presenting superior performance when compared with the others. So the variety of cow rib is recommended for conditions Coremas - PB.

Keywords: creole, productivity, semiarid, Vigna unguiculata, family farming

\footnotetext{
*Autor para correspondência

Recebido para publicação em 20/12/2014; aprovado em 25/01/2015

Lic. em Ciências Agrárias, pela UFPB, Universidade Federal da Paraíba. E-mail: artecor.coremas@ gmail.com

Lic. Em Ciências Agrárias, pela UFPB, Mestre em Agronomia/Fitotecnia pela UFC e Doutorando em Ciências Agrárias pela UFRB. E-mail:

lucas18kennedy@gmail.com
} 


\section{INTRODUÇÃO}

O nordeste caracteriza-se por apresentar uma agricultura em sua grande maioria de base familiar, onde sua produção é consumida e o excedente comercializado. Dentre as culturas produzidas o feijão caupi caracteriza-se sendo uma das mais importantes, principalmente pela sua rusticidade ao clima semiárido e pelo seu elevado teor nutricional, servindo como fonte de proteínas e carboidratos (LIMA, 2014). O feijãocaupi Vigna unguiculata(L.) Walp. conhecido pela cultura popular como feijão costela-de-vaca, feijão macassar, feijãode-corda, sempre-verde, é cultivado principalmente na região nordeste e norte do Brasil (SILVA \& NEVES, 2011).

A espécie gera renda para milhares de famílias das regiões Norte e Nordeste do Brasil no processo de produção e comercialização principalmente. Em função das suas características de rusticidade, adaptabilidade ampla, precocidade e capacidade de produzir em ambientes desfavoráveis, o feijão-caupi é uma cultura que tem grandes perspectivas, frente a escassez de alimento que há nos países em desenvolvimento, entre os quais se inclui o Brasil, em particular, a região Nordeste (SOUZA et al., 2013).

Além da utilização para o consumo in natura, principalmente na forma de grãos secos ou verdes, o feijãocaupi é utilizado também como forragem, feno, ensilagem, farinha para alimentação animal, como adubação verde, proteção do solo (ROCHA, 2009).

Na região semiárida do Nordeste e em áreas isoladas da Amazônia, o feijão-caupi constitui a principal cultura de subsistência. Em virtude de suas características de rusticidade e precocidade é considerada uma planta adaptada as condições de clima da região semiárida (OLIVEIRA et al., 2002). Entretanto apesar de adaptadas às condições ambientais de cultivo, apresentam produtividade média de apenas $355 \mathrm{~kg} \mathrm{ha}^{-1}$ (CONAB, 2012).

$\mathrm{A}$ indicação de cultivares adaptadas às condições de solo e clima da região proporciona maior segurança ao produtor em função do maior rendimento. Neste sentido, é importante e necessário à avaliação de novas linhagens e cultivares no ambiente de exploração do agricultor, levando-se em conta o manejo, sistema de produção, nível tecnológico destes em condições locais, de forma a identificar os materiais genéticos que melhores respostas apresentarem em termos de componentes de produção e produtividade de grãos, bem como às exigências e avaliações dos agricultores e suas famílias e do comércio da região, principalmente cor e tamanho do grão, facilidade no beneficiamento, tempo para o cozimento e sabor (SANTOS, 2013).

No mercado brasileiro existem cultivares de boa aceitação comercial. Entretanto, não há um programa nacional que vise a avaliação e recomendação de cultivares em ambientes específicos. Estudos sobre novas opções de cultivares são necessários (OLIVEIRA et al., 2002). Assim este trabalho teve por objetivo avaliar a produtividade de variedades de feijão-caupi em cultivo de sequeiro no município de Coremas-PB.

\section{MATERIAL E MÉTODOS}

O experimento foi realizado na comunidade quilombola do sítio Barreiras município de Coremas estado da Paraíba, na propriedade do agricultor Luiz Jorge de Amorim, entre
Fevereiro e Maio de 2014. O estudo foi conduzido às margens do açude Mãe D'água, onde o acesso ao local foi feito de barco. Coremas ocupa uma área de $461,2 \mathrm{~km}^{2}$. A sede municipal apresenta uma altitude de $220 \mathrm{~m}$ e coordenadas geográficas de $37^{\circ} 56^{\prime} 45^{\prime}$ ' longitude oeste e $07^{\circ} 00^{\prime} 50^{\prime}$ ' de latitude sul. As chuvas são escassas, caracterizadas por um regime pluviométrico que além de baixo é irregular com médias anuais de $882,3 \mathrm{~mm} / \mathrm{ano}$, contendo valores mínimos e máximos de 342,7 e 1837,7 mm/ano respectivamente (MASCARENHAS et al., 2005).

O experimento foi conduzido no período de fevereiro a maio de 2014, registrando um acumulado de chuvas de 506 mm segundo dados da EMATER Figura 1 (EMATER, 2014).

Figura 1. Índice Pluviométrico $(\mathrm{mm})$ de Fevereiro à Maio de 2014 no município de Coremas-PB.

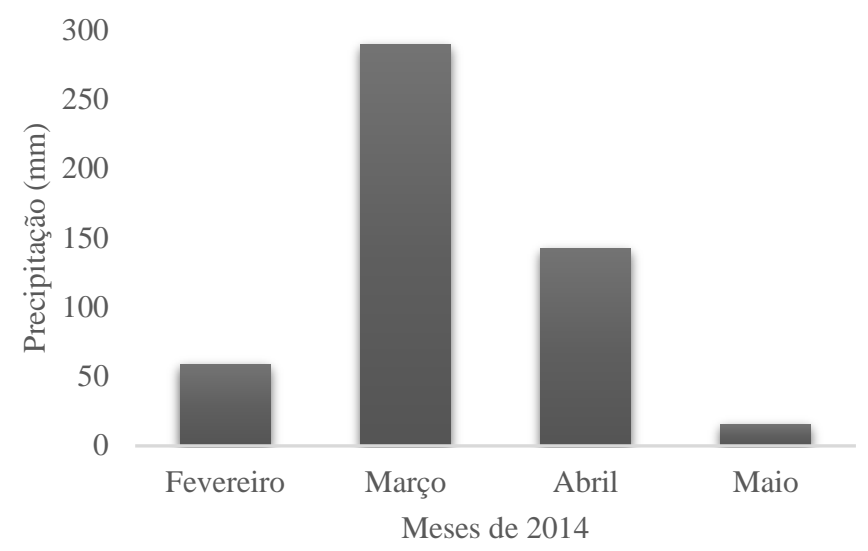

Fonte EMATER

O trabalho foi constituído por quatro tratamentos que foram as variedades de feijão-caupi (sempre-verde, roxinho, costela-de-vaca e garanjão) em cinco repetições. A variedade sempre verde é uma cultivar comercializada no mercado e fornecida pelo órgão governamental EMATER-PB aos pequenos produtores da região. As variedades crioulas roxinho, costela-de-vaca e garanjão, são conservadas e selecionadas pelo agricultor Luiz Jorge a muitos anos através de processo de seleção massal.

A área experimental foi composta por cinco blocos medindo cinco metros de comprimento. $\mathrm{O}$ espaçamento foi de $1,0 \mathrm{~m} \times 0,50 \mathrm{~m}$, onde foram semeadas cinco sementes por cova aberta manualmente por meio de chibanca. Previamente a instalação do experimento foi realizada adubação com esterco bovino na proporção de 10 t/ha.

As variáveis analisadas aos 50 dias após semeadura foram produtividade de grãos ( $\left.\mathrm{PG} / \mathrm{t} \cdot \mathrm{ha}^{-1}\right)$, comprimento médio de vagem $(\mathrm{CV} / \mathrm{cm})$, número de grãos por vagem $(\mathrm{NGV})$, peso médio de vagem (PMV/g), massa de 100 grãos (MCG). Para análise de variância foi adotado o delineamento em blocos casualizados com cinco repetições. Os dados obtidos foram submetidos a análise de variância pelo teste $\mathrm{F}$ aos níveis de $5 \%$ e $1 \%$ de probabilidade e as médias comparadas pelo teste de Tukey a $5 \%$ de probabilidade, por meio do Software Assistat 7.3. 


\section{RESULTADOS E DISCUSSÃO}

Na Tabela 1 observa-se o resumo das análises de variância das características produtivas comprimento de vagem, número de grão por vagem, massa seca de vagem, massa de 100 grãos e produtividade de grão (Tabela 1). Foi observada variação significativa para todas as variáveis analisadas, onde apenas para a massa seca de vagem foi observada variação ao nível de $(\mathrm{p}<0.05)$ de probabilidade as demais, foram significativas ao nível de $1 \%$ de probabilidade.
As variedades obtiveram comprimento médio de vagem de $18,55 \mathrm{~cm}$, sendo considerada uma excelente média, tendo em vista a forma de condução do experimento que foi em regime de sequeiro, nessa situação, as plantas estão sujeitas a uma série de interferências bióticas e abióticas. A produtividade média também ficou bem acima da média nacional $(1.093,06)$ que segundo dados da CONAB foi de 355 $\mathrm{kg} \mathrm{ha}^{-1}$ no ano de 2012 (Tabela 1 ).

Tabela 1. Resumo da análise de variância das características produtivas comprimento médio de vagem (CV), número de grãos por vagem (NGV), massa seca de vagem (MSV), massa de 100 grãos (MCG) e produtividade de grãos (PG) obtidos no experimento conduzido as margens do açude Coremas/Mãe d'água Coremas-PB

\begin{tabular}{lcccccc}
\hline FV & gl & CV $(\mathrm{cm})$ & NGV & MSV $(\mathrm{g})$ & MCG $(\mathrm{g})$ & PG $\left.(\mathrm{kg} \mathrm{ha})^{-1}\right)$ \\
\hline Bloco & 4 & $0,38952^{\mathrm{ns}}$ & $0,086^{\mathrm{ns}}$ & $0,08412^{\mathrm{ns}}$ & $7,06575^{\mathrm{ns}}$ & $12764,36735^{\mathrm{ns}}$ \\
Tratamento & 3 & $9,15631^{* *}$ & $10,088^{* *}$ & $0,99198^{*}$ & $33,03600^{* *}$ & $486360,17989^{* *}$ \\
Erro & 12 & 0,19489 & 0,146 & 0,03405 & 3.01808 & 17309,74264 \\
\hline Média & & 18,55 & 13,402 & 3,64 & 21,04 & 1093,06 \\
\hline CV $(\%)$ & & 2,38 & 2,86 & 5,07 & 8,26 & 12,04 \\
\hline
\end{tabular}

** significativo ao nível de $1 \%$ de probabilidade, *significativo ao nível de $5 \%$ de probabilidade ns não significativo

O comprimento médio de vagens não variou estatisticamente para as variedades costela de vaca, sempre verde e roxinho, com média de 19,$63 ; 19,12$ e 18,89 respectivamente (Tabela 2). Esses resultados foram superiores aos alcançados por (SANTOS et al. 2009) que atingiu 17,88 $\mathrm{cm}$. Esse comprimento médio, encontra-se dentro dos padrões estabelecidos comercialmente por Pereira et al. (1992), Silva \& Oliveira (1993) e Miranda et al. (1996) de aceitação no mercado consumidor.

A variedadi criola costela de vaca, apresentou rendimento superior quando comparado com as demais variedades estudadas, para o número de grãos por vagem, massa seca de vagem e número de 100 grãos (Tabela 2), contrapondo a afirmação de Aquino e Nunes (1983), Maia et al. (1986) que atribuem a baixa produtividade do feijão caupi no Nordeste à utilização de variedades tradicionais, de baixa qualidade genética. Os autores ao apresentar essa afirmativa não levaram em consideração os processos de adaptação das variedades crioulas ao longo do tempo, que através da seleção massal, os pequenos agricultores selecionam os genótipos que melhor se adaptam as condições locais, criando uma variedade específico ao ambiente de cultivo, com isso, esses variedades especificas apresentam rendimento superior quando comparado as cultivares de elevado potencial genético.

A variedade costela de vaca foi a única com rendimento superior aos $1000 \mathrm{~kg} \mathrm{ha}^{-1}$, demostrado que a mesma encontrase adaptada as condições locais de Coremas - PB. Apesar das limitações genéticas associadas as variedades crioulas, o processo de adaptação desses genótipos contribui para que as mesmas apresentem elevado rendimento quando comparado com cultivares comerciais, que só expressaram seu máximo potencial em condições específica de clima e solo.

Os processos de seleção massal realizados pelos agricultores de forma empírica ao longo do tempo, certamente contribuíram para que a variedade costela de vaca alcançasse maior rendimento.

Tabela 2. Comprimento médio de vagem (CV), número de grãos por vagem (NGV), massa seca de vagem (PMV), massa de 100 grãos (MCG) e produtividade de grãos (PG) obtidos no experimento conduzido as margens do açude Coremas/Mãe d'água Coremas-PB

\begin{tabular}{lccccc}
\hline Cultivares & CV $(\mathrm{cm})$ & NGV & MSV $(\mathrm{g})$ & MCG $(\mathrm{g})$ & PG $\left(\mathrm{kg} \mathrm{ha}{ }^{-1}\right)$ \\
\hline Costela de Vaca & $19,63 \mathrm{a}$ & $15,29 \mathrm{a}$ & $4,29 \mathrm{a}$ & $24,76 \mathrm{a}$ & $1556,67 \mathrm{a}$ \\
Sempre Verde & $19,12 \mathrm{a}$ & $13,71 \mathrm{~b}$ & $3,43 \mathrm{~b}$ & $18,86 \mathrm{~b}$ & $883,12 \mathrm{~b}$ \\
Garanjão & $16,58 \mathrm{~b}$ & $12,33 \mathrm{c}$ & $3,30 \mathrm{~b}$ & $20,12 \mathrm{~b}$ & $984,04 \mathrm{~b}$ \\
Roxinho & $18,89 \mathrm{a}$ & $12,28 \mathrm{c}$ & $3,55 \mathrm{~b}$ & $20,42 \mathrm{~b}$ & $948,42 \mathrm{~b}$ \\
\hline
\end{tabular}

Médias seguidas pela mesma letra na coluna não diferem entre si pelo teste de Tukey ao nível de $5 \%$ de probabilidade

Estudo desenvolvido por Santos et al. (2013) avaliando o comportamento de cultivares de feijão-caupi nas condições do Agreste paraibano observaram que para o comprimento de vagem, a cultivar BRS Marataoã não diferiu estatisticamente da BRS Potiguar e Miranda IPA-207, sendo superiores aos demais materiais genéticos estudados. Torres Filho et al. (2013) não encontraram diferenças entre 16 linhagens e 4 cultivares com uma média 17,83cm; Cavalcante et al. (2013) encontraram valores entre $16,0 \mathrm{~cm}$ para a linhagem BRS Juruá a 21,6 cm para a linhagem MNC02-677F-2, com média geral de 19,6 cm. Sousa et al. (2013) obtiveram variação de $18,49 \mathrm{~cm} \quad(\mathrm{MNC02}-676 \mathrm{~F}-3)$ a 23,04 cm (BRS Tumucumaque), com média geral de $20,51 \mathrm{~cm}$.

Para número de grãos por vagem, Santos et al. (2013) destaca a cultivar BRS Xiquexique (13,0 grãos). Sendo similar aos observados aqui. Resultados similares também foram observados Santos et al. (2009) e Santos et al. (2011). Santos et al. (2013) com os valores mais elevados de grãos por vagem, ficando a média geral em 11,36 grãos por vagem. Torres Filho et al. (2013) não encontraram efeito de 16 
linhagens e 4 cultivares sobre essa característica com uma variação de 8,65 a 12,60 e uma média de 11,85 grãos por vagem. Sousa et al. (2013) obtiveram valores entre 10,75 (BRS Itaim) a 14,85 grãos por vagem (BRS Tumucumaque), com média geral de 13,04 grãos por vagem.

Para massa seca de vagens, Santos et al. (2013), destaca a BRS Potengi. Santos et al. (2011), avaliando cultivares de feijão-caupi, evidenciaram que a cultivar BRS Marataoã não diferiu da BRS Paraguaçu. Santos et al. (2013) afirmaram que a cultivar Miranda IPA-207 (4,32 g) e a Canapu (4,23 g) foram superiores as demais com uma média geral de $2,95 \mathrm{~g}$.

Para massa de 100 grãos, Santos et al. (2013) observou-se que a cultivar local BRS Amapá, com a massa de 29,46 g foi superior as demais materiais genéticos avaliados. No entanto segundo os autores, a BRS Amapá embora tenha apresentado maior massa de 100 grãos, esta apresentou menor número de grãos por vagem que pode ter contribuído para a menor produtividade de grãos desse material.

A produtividade média obtida por Santos et al. (2013) entre as cultivares foi de $892 \mathrm{~kg} \mathrm{ha}^{-1}$, ficando abaixo aos resultados obtidos aqui $(1093,06)$, os autores constataram que a cultivar Marataoã foi a que apresentou maior produtividade com $1.201 \mathrm{~kg}$ ha, ficando abaixo ao rendimento obtido pela cultivar constala de vaca $1.556 \mathrm{~kg}$ ha.

Em condições que se empregam baixas tecnologias de cultivo, as variedades comerciais podem apresentar desempenho próximo ou mesmo inferior às variedades crioulas. Ademais, o uso de variedades locais possui diversas outras vantagens ligadas à sustentabilidade da produção como resistência a doenças, pragas e desequilíbrios climáticos, e podem ter as sementes armazenadas para as safras seguintes, o que diminui o custo de produção (CARPENTIERI-PÍPOLO et al., 2010). Segundo Cecarelli et al. (1994), o ganho ambiental também é superior, uma vez que o uso de variedades crioulas, adaptadas localmente, mantém a diversidade genética das espécies, podendo servir de fonte para o melhoramento.

Segundo Abreu et al. (2007), o uso das variedades crioulas, o que confere baixo custo, constitui numa alternativa para a sustentabilidade dos pequenos agricultores. Além do que, o melhoramento destas variedades pode ser feito nas propriedades pelos próprios agricultores que detém alto conhecimento destes materiais crioulos.

\section{CONCLUSÕES}

A variedade costela de vaca foi a que apresentou rendimento superior.

Costela-de-vaca é recomendada para o plantio nas condições de Coremas - PB.

As demais variáveis apresentaram comportamento semelhante a cultivar sempre verde, se comportaram de forma satisfatória.

\section{AGRADECIMENTOS}

Os autores agradecem ao agricultor Luiz Jorge de Amorim pela área experimental e colaboração na condução da pesquisa.

\section{REFERÊNCIAS BIBLIOGRÁFICAS}

ABREU, L.; CANSI, E.; JURIATTI， C. Avaliação do rendimento sócio-econômico de variedades crioulas e híbridos comerciais de milho na microregião de Chapecó. Revista Brasileira de Agroecologia, v. 2, n. 1, p. 1230-1233, 2007.

AQUINO, S.F.; NUNES, R.P. Estrutura genética de populações de caupi e suas implicações no melhoramento genético através da seleção. Pesquisa Agropecuária Brasileira, Brasília, v. 18, n. 4, p. 399$412,1983$.

CAlvalcante, E. da S.; GÓES, A. C. P.; MELÉM JÚNIOR, N. J.; ROCHA, M. de M. R.; FREIRE FILHO, F.R. Avaliação de linhagens de feijão-caupi no Amapá. In: III CONGRESSO NACIONAL DE FEIJÃO-CAUPI. Resumo. Recife, PE. 22-24 abril de 2013. 5p.

CARPENTIERI-PÍPOLO, V.; SOUZA, A. de; SILVA, D. A. da; BARRETO, T. P.; GARBUGLIO, D. D.; FERREIRA, J. M. Avaliação de cultivares de milho crioulo em sistema de baixo nível tecnológico. Acta Scientiarum. Agronomy Maringá, v. 32, n. 2, p. 229233, 2010.

CECCARELLI, S. Specific adaptation and breeding for marginal conditions. Euphytica, v. 77, n. 3, p. 205-219, 1994.

CONAB. COMPANHIA NACIONAL DE ABASTECIMENTO. Acompanhamento da safra brasileira: Grãos, sexto levantamento, safra 2011/2012, março/2012. Companhia Nacional de Abastecimento. Brasília: Conab, 26p. 2012.

EMATER Paraíba. Empresa de Assistência Técnica e Extensão Rural da Paraíba. Pluviometria. Disponível em: < http://www.emater.pb.gov.br/ > Acesso em: 04/06/2014.

LIMA, L. K. S. Desenvolvimento do feijão caupi em função da utilização de resíduo da indústria do café como fonte de potássio. Dissertação. Mestrado em Agronomia/Fitotecnia. Universidade Federal do Ceará. 2014.

MAIA, A.F.; ASSUNÇÃO, M.V.; ALVES, J.F. Influência do método de debulha e da umidade na produção de sementes de feijão de corda. Ciência Agronômica, Fortaleza, v. 17, n. 2, p. 91 - 100, 1986.

MASCARENHAS, J. de C., BELTRÃO, B. A., JUNIOR, L. C. DE S., MORAIS, F. DE, MENDES, V. A., \& MIRANDA, J. L. F. de. Projeto cadastro de fontes de abastecimento por água subterrânea. 2005.

MIRANDA, P.; COSTA, A.F.; OLIVEIRA, L.R.; TAVARES, J.A.; PIMENTEL, M.L.; LINS, G.M.L. Comportamento de cultivares de Vigna unguiculata (L) Walp., nos sistemas solteiro e consorciado. IV — tipos ereto e semi-ereto. Pesquisa Agropecuária Pernambucana, Recife, v. 9, n. especial, p. 95-105, 1996.

OLIVEIRA, A. P. de; TAVARES SOBRINHO, J.; NASCIMENTO, J. T. ALVES, A. U.; ALBUQUERQUE, I. C. de; BRUNO, G. B. Avaliação de linhagens e cultivares de feijão-caupi, em Areia, PB. 
Horticultura Brasileira, Brasília, v. 20, n. 2, p. 180-182, junho 2002.

PEREIRA, J.A.; BELARMINO FILHO, J.; SANTOS, J.F.; ARANHA, V.S. Caracteres agronômicos e suas correlações em linhagens de feijãomacassar. EMEPA, 1992 (Boletim de pesquisa 06).

ROCHA, M. de M. et al. Controle genético do comprimento do pedúnculo em feijão-caupi. Pesquisa Agropecuária Brasileira, Brasília, v. 44, n. 3, p. 270 - 275, 2009.

SANTOS, J. F. dos. Produtividade de cultivares de feijãocaupi no Agreste Paraibano. Tecnol. \& Ciên. Agropec., João Pessoa, v.7, n.4, p.31-36, dez. 2013.

SANTOS, J. F. dos; GRANGEIRO, J. I. T; OLIVEIRA, M. E. C. de. Produção de feijão-macassar no Brejo Paraibano. Tecnologia \& Ciência Agropecuária. João Pessoa, PB, v.5, n.2, p.17-21, jun. 2011.

SANTOS, J.F. dos; GRANGEIRO, J.I.; CARDOSO, M.J.; BASTOS, E.A. Desempenho produtivo de cultivares de feijão-caupi no agreste paraibano. In: III CONGRESSO NACIONAL DE FEIJÃO-CAUPI. Resumo. Recife, PE. 22-24 abril de 2013, 4p.

SANTOS, J.F. dos; GRANGEIRO, J.I.T.; BRITO, C.H.; SANTOS, M.C.C.A. Produção e componentes produtivos de variedades de feijão-caupi na microrregião cariri paraibano. Engenharia Ambiental, Espírito Santo do Pinhal, v.6, n.1, p.214-222, jan./abr. 2009a.

SILVA, J. a. L.; Neves, J. a. Produção de feijão-caupi semiprostrado em cultivos de sequeiro e irrigado. Revista Brasileira de Ciências Agrárias - Brazilian Journal of Agricultural Sciences, 6(1), 29-36.v.6, ano 1, p. 748, 31 março 2011.

SILVA, P.S.L.; OLIVEIRA, C.N. Rendimentos de feijão verde e maduro de cultivares de caupi. Horticultura Brasileira, Brasília, v. 11, n. 2, p 133-135, 1993.

SOUSA, R.R. de; OLIVEIRA, D.G.; ROCHA, M. de M.; SILVA, K.J.D. e; SOUSA, J.L.M.; COSTA, M. de M. Variabilidade genética e potencial agronômico de genótipos De feijão caupi de porte semiereto/ereto no município de Teresina-PI. In: III CONGRESSO NACIONAL DE FEIJÃO-CAUPI. Resumo. Recife, PE. 22-24 abril de 2013. 5p.

SOUZA, A. A. de; SILVA, K. J. D.; ROCHA, M. de M.; SOUZA, V. B. de; OLIVEIRA, M. B. de; CARVALHO, A. J. de. Componentes de produção de linhagens selecionadas de feijão-caupi de porte prostrado e semiprostrado no norte de Minas Gerais. Resumo. Recife, PE. 22-24 abril de 2013. 5p.

TORRES FILHO, J. et al. Avaliação de genótipos de feijãocaupi ereto e semi-ereto em diferentes épocas no município de Mossoró RN. In: III CONGRESSO NACIONAL DE FEIJÃOCAUPI. Resumo. Recife, PE. 22-24 abril de 2013. 5p. 